\title{
Hypertelorism, Teebi type
}

INSERM

\section{Source}

INSERM. (1999). Orphanet: an online rare disease and orphan drug data base.

Hypertelorism, Teebitype. ORPHA:1519

Teebi type hypertelorism is a rare genetic disease characterized by hypertelorism with facial features that can closely resemble craniofrontonasal dysplasia (see this term), such as prominent forehead, widow's peak, heavy and broad eyebrows, long palpebral fissures, ptosis, high and broad nasal bridge, short nose, low-set ears, natal teeth, thin upper lip and a grooved chin, as well as limb (i.e. fifth-finger clinodactyly, pes adductus, mild interdigital webbing), urogenital (i.e. bilateral cryptorchidism and shawl scrotum in males) and umbilical (i.e. hernia/small omphalocele) anomalies and cardiac (i.e. ventricular or atrial septal defect, patent ductus arteriosus) defects. Additional findings such as polycystic kidneys and iridochorioretinal colobomas have also been reported and psychomotor development is normal. The facial features can also resemble Aarskog and Opitz G/BBB syndromes (see these terms). 